\title{
Mapping Mars’s Eastern Valles Marineris
}

\author{
Eian Ray, ${ }^{1}$
}

1. eianray@gmail.com; linkedin.com/in/eianray; https://marylhurst.academia.edu/EianRay

Abstract: The purpose of this mapping project was to create a cartographically accurate representation of an Exploration Zone at the Eastern Valles Marineris outflow region within equatorial Mars. There are numerous problems associated with mapping planetary surfaces. Data and imagery for Exploration Zones at a spatial and spectral resolution sufficient for human landing site evaluation and traverse planning have not been acquired yet. Additionally, as technology evolves, it is very difficult to extrapolate which mapping technologies will be used in the near and far future. In order to create this map, assumptions about the future of mapping had to be made, publicly released data for the area of interest had to be sourced, and data analysis had to be performed. One of the key elements of a successful mission is how to communicate the geospatial aspects of the mission planning process to the general public. The results show that using existing data and traditional static cartographic methods, even extra-terrestrial geographic discoveries can be made and disseminated to the public in an attractive and easily understood format.

Keywords: Mars, Valles Marineris, cartography, areography, planetary mapping, naming conventions

\section{Introduction to Mapping Project}

Preparations for a Human Exploration of Mars has been underway since the 1960's through national and multinational programs, most notably those of the United States, United Kingdom, European Union, and the former Soviet Union (NASA, 2016). More recently many of the associated costs of exploration have been driven down (Chaikin, 2012) and many private, corporate, and non-profit organizations have picked up the torch of Martian exploration. Remote exploration of Mars has also recently entered the public sphere in the form of imagery from NASA and ESA, Google Earth’s Mars, and citizen efforts afforded by the collaborative nature of the internet.

This mapping exercise of the Eastern Valles Marineris region of Equatorial Mars represents such a collaborative effort in the form of an online map design competition. The competition encouraged both professional and hobbyist cartographers 
from around the world to participate in planning the first human mission to Mars by choosing one of NASA's 47 proposed landing sites (Exploration Zones) to map in detail. The style and design of each map entry is the cartographer's prerogative (ICA CPC, 2016).

All 47 potential exploration zones were carefully considered. Although they all met the basic criteria set forth by NASA, some areas were more inspiring than others. Ultimately, the Eastern Valles Marineris outflow area was chosen because of its many similarities to geographic features in the Columbia Basin in Eastern Washington State. Coulees, escarpments, and flood plains in Valles Marineris are eerily reminiscent of those in the Columbia Basin and these similarities may assist the identification and extraction of useful resources. The extreme topography and relatively narrow mouth of this part of the valley create many geologic and geographic areas of interest within travelable distance of the landing site resulting in a potentially higher return on investment in terms of habitability and research relative to other parts of the planet.

\section{Map Considerations}

Projecting the mapping needs of human explorers on Mars is not an easy task, however the author believes certain assumptions can be made. As of the writing of this paper, interactive digital maps on mobile devices and the web make up a growing share of map usage relative to traditional static maps. Paper maps, by contrast, are falling further out of favor due to the cost of creating, updating, and printing, as well as their unwieldiness in the field and the difficulty of use in harsh environments where they may become degraded or lost. Interactive digital maps of some variety are almost certainly going to be the mapping technology of choice in future Martian exploration, both on Earth and for astronauts carrying out field work on the Martian surface. Several mapping technologies were considered for the development of the Eastern Valles Marineris Exploration Zone map. They are:

- $\quad$ Augmented Reality (AR)

- $\quad$ Mixed Reality / Virtual Reality (VR)

- Web Geographic Information System (GIS)

Augmented reality using a heads-up display (HUD) system or other mobile device will be further developed for space exploration in coming years. Whether this technology is integrated into the helmets of the explorers or used only on mobile devices in the field and/or the lab is unknown at this time. Already such systems have been developed for Earthly navigation, stargazing, and other educational purposes where an understanding of place is enhanced by overlying it with additional, non-physical information. Examples of these augmented reality interfaces are Star Chart, a popular stargazing app for iOS, and the heads-up displays found in many 
vehicles that aid in navigation (Newcomb, 2015). Other apps such as Neon App allow users to locate places and other users by peering through the display of the device, The hardware and software ecosystems for this technology are already in place with a multiplicity of commercial and experimental products and services available. It would require only simple modification to extend them to extra-terrestrial purposes.

A combination of augmented reality and virtual reality known as "mixed reality" is another potential option and will also likely be used in future exploration. Since virtual reality doesn't actually require an explorer to be on site, it will likely be used as a remote sensing technology, allowing explorers to familiarize themselves with the environment they will soon set foot prior to arrival or to perform research remotely. The JPL project OnSite uses the Microsoft Hololens to project humans and equipment onto a Martian landscape, which can be viewed by multiple individuals simultaneously for collaborative observations and research almost as if they were on the planet itself. (Jet Propulsion Laboratory, 2015).

A web GIS system was also considered due to its high utility to online users. Multiple users from multiple fields would be able to peruse the exploration zone and be able to toggle on or off those layers which are deemed important for their respective projects or interests. Although this seemed to be the most useful form of mapping for Martian mapping purposes, it was decided against because the author desired to create a digital map that could be printed into a cartographically pleasing paper map, a function that is not easily done with a web GIS. Although printing is possible with a web GIS, quality control would no longer within the purview of the author, something the author was unwilling to relinquish to non-cartographer users.

In the end it was decided that a standard GIS map of the Eastern Valles Marineris exploration zone would suffice as a medium to intrigue the public as well as convey new cartographic ideas to researchers. This method of mapping also allows the author to have full control over the final output product. The final map product would be created using ESRI's ArcGIS suite, and would be available in both PDF and TIFF form so that it could be shared online or on mobile devices in static form as well as being able to be printed off as a poster. The GIS data layers could also be made available digitally so they could be integrated into future mapping exercises by the author, or others. Furthermore, these layers could be integrated into an augmented reality or web GIS system at some point in the future since those layers will already be georeferenced. These layers could be considered "legacy" data, as they can slowly be migrated into newer mapping technologies before ultimately being replaced with superior datasets. 


\section{Map Construction}

The drafting of this map was an iterative process which involved the creation of six drafts. Each draft was carefully reviewed by volunteers who were knowledgeable in GIS, cartography, and graphic design. Non-GIS professionals were also consulted on ease of understanding and the ability to interpret the message that the map was attempting to convey. Copies were printed and given to these reviewers to mark on and report back to the author for modification or correction. Issues that were addressed by these individuals included symbology, color schemes, background color ramp, labeling, contour intervals, font choice, and layout. During each iterative cycle the map improved in both content and visual appeal until a final version emerged for submission.

\subsection{Base Datasets Used}

This mapping exercise started with four publicly available base datasets from the USGS Planetary GIS Data Server (PIGDA).

- $\quad$ Digital elevation model (DEM), acquired by the Mars Orbiter Laser Altimeter (MOLA) (Neumann et al, 2003) which accompanied the Mars Global Surveyor from 1999 to 2001 and has a horizontal accuracy of approximately 100 meters and a vertical accuracy of approximately 3 meters (Lemoine et al, 2001)

- Mars global hillshade, a derivative product of the MOLA DEM. Downloadable from PIGDA or created fresh using ESRI's ArcGIS.

- Robbins Crater Database. A databased compiled by Stuart Robbins to capture craters larger than $1.0 \mathrm{~km}$. It currently contains over 640,000 crater points (Robbins, 2013)

- USGS IAU nomenclature shapefile. A GIS file that contains over 1800 named places on Mars that were extracted from the USGS Gazetteer of Planetary Nomenclature (USGS GIS metadata, 2016).

Both the digital elevation model (DEM) and the derived hillshade raster were obtained and used as the cartographic base layers and as datasets used in subsequent analysis and the development of secondary GIS data products such as contours and points of interest. Since these are global datasets and already georeferenced, they represent the most accurate topography of Mars available (USGS, 2014) and were useful in identifying the Eastern Valles Marineris region as the author's exploration zone of interest.

The Robbin's Crater Database was modified from a point feature class into a polygon feature class to better indicate the perimeter of the craters instead of only the crater centroid. This was done by buffering the crater points using the diameter 
field within the attribute table to create circular polygons of the correct diameter. These polygons were then saved as a separate feature class. Later it was decided that the circular polygons should more closely match the actual rim of the crater more closely for cartographic purposes and so each crater within the map's data frame was manually adjusted.

\subsection{Imagery}

Google Earth's Mars system was an invaluable resource comprised of imagery from the HiRISE, CTX, MOC, HRSC, and CRISM camera systems which originated from NASA and the ESA. The resolution of the imagery easily allowed the identification of features not otherwise discernable from the MOLA DEM. For this mapping exercise imagery from HRSC, MOC, and CTX were examined, but not of CRISM or HiRISE due to lack of imagery within the exploration zone. Below is a table comparing the MOLA DEM quality with the aforementioned imagery collections.

Table 1. Available imagery to compare to MOLA DEM

\begin{tabular}{l|r|r} 
Name & Resolution & Mission \\
\hline $\begin{array}{l}\text { Mars Orbiter Laser Altimeter } \\
\text { (MOLA) DEM }\end{array}$ & $463 \mathrm{~m}$ & NASA's Mars Global Surveyor \\
$\begin{array}{l}\text { Context Camera (CTX) } \\
\text { mars Orbital Camera (MOC) }\end{array}$ & $\begin{array}{r}\text { NASA's Mars Reconnaissance } \\
\text { Orbiter }\end{array}$ \\
$\begin{array}{l}\text { High Resolution Sterio Camera } \\
\text { Mas }\end{array}$ & $2-12 \mathrm{~m}$ & NASA's Mars Global Surveyor \\
\end{tabular}

(HRSC). 


\subsubsection{Tools for Geologic Investigations}

In the north portion of the exploration zone along the west rim there are several landslides which are labeled on the map, but which are difficult to identify without first examining a satellite imagery of the same area.

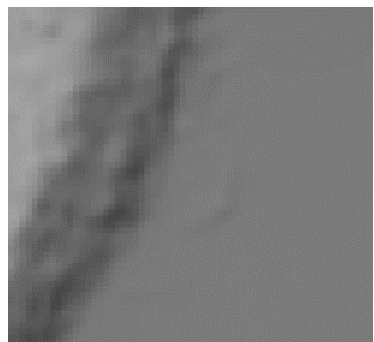

Fig. 1. Landslides within the exploration zone as seen in the MOLA DEM data. Difficult to identify at 463-meter resolution.

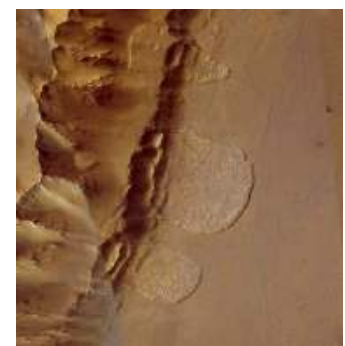

Fig. 2. Landslides as seen in 6-meter CTX imagery.

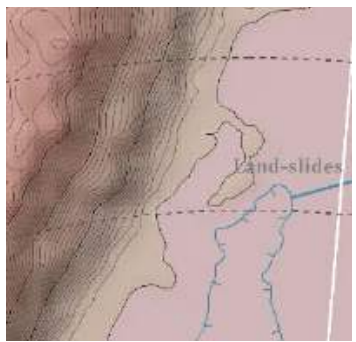

Fig. 3. Landslides captured from imagery and delineated on the Eastern Valles Marineris map.

The same is true for a great number of small craters which are not picked up in detail from the MOLA DEM. The most surprising find from examining the Martian imagery was what appears to be a paleo lake bed in the southwest quadrant of the exploration zone (Google Earth's Mars, 2016). It was discovered using CTX imagery from Google Earth's Mars. Using the same program, it was measured to be approximately 60 square miles in area and has a well delineated shoreline (Google Earth’s Mars, 2016).

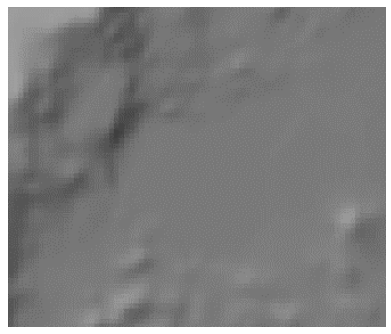

Fig. 4. Lake Elise as seen in the MOLA DEM data. Difficult to identify at 463-meter resolution

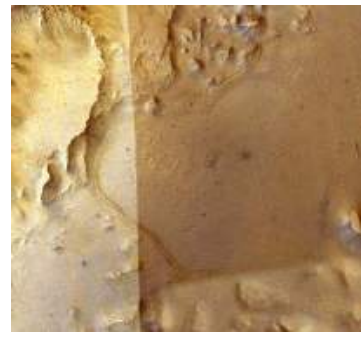

Fig. 5. Lake Elise as seen in 6-meter CTX imagery.

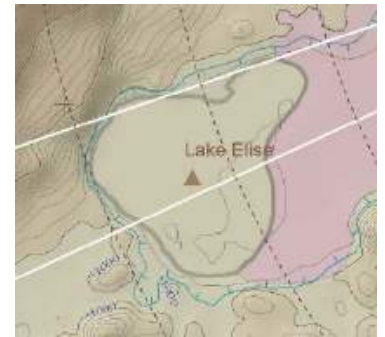

Fig. 6. Lake Elise captured from imagery and delineated on the Eastern Valles Marineris map. 
Lake Elise* was captured from the imagery using Google Earth/Mars to delineate its perimeter as a polyline and then exporting it as a KML file. This KML file was then converted into a shapefile using ArcMap's KML to Layer tool.

\subsection{Derivative Analysis \& Datasets}

A slope raster was created using ArcGIS Surface Analyst toolset. It was used to identify potential low-slope areas. Two were identified as having potential, one had a slope of $16.1^{\circ}$ and with the other had a slope of $6.5^{\circ}$ from which to access the Valles Marineris rim. The more gradual identified rim route is approximately $270 \mathrm{~km}$ long while the alternate, steeper, option is only $79 \mathrm{~km}$ each way.

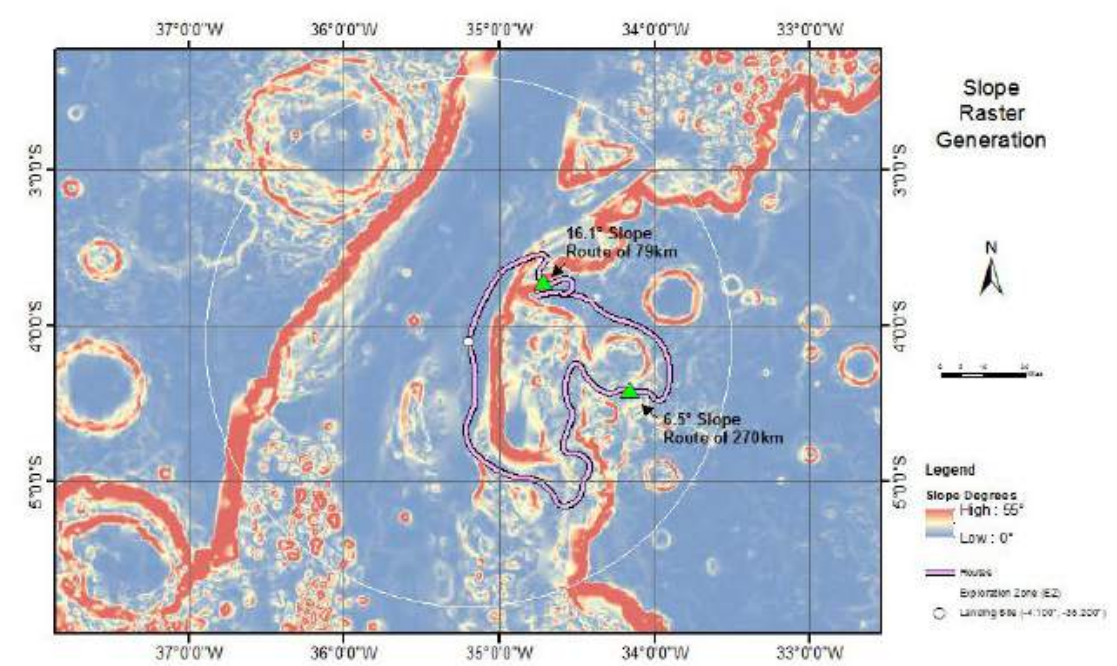

Fig. 7. Map showing a slope raster generated from the MOLA DEM using ESRI's ArcGIS Spatial Analyst toolset. Although this graphic isn't included on the Eastern Valles Marineris Exploration Zone map, it was used to identify the most graduate passes out of the valley to the top of the rim.

A series of contours were generated at 10, 100, and 1000 meter intervals by processing the MOLA DEM data using the ArcGIS contour creation tool for each desired interval. Due to the scale of the map, the 100 and 1000 meter intervals were the most useful for illustrating topography. Both were generated above and below the zero elevation datum within the vicinity of the Eastern Valles Marineris exploration zone. The contours helped indicate topographical extent and helped interpret the shading on the hillshade layer. The contours also aided in initially identifying a topographic depression on the valley floor, an indication of the origin of Valles Marineris, that of a rift valley. After discovering the presence of the depression, a 
local10-meter contour layer was created to increase the resolution of the depression contour and to help tease out the location of the valley's drainage channel north of the depression. Because this depression represents a basin, the identification of a central channel within the depression was not possible. This depression contour is at approximately $-3,990 \mathrm{~m}$. Incidentally, the depression contour makes up the western boundary of Lake Elise showing that the lake exists within a low lying area with no apparent drainage. This low lying area appears to be a rift basin, a hallmark feature of some rift valleys on Earth.

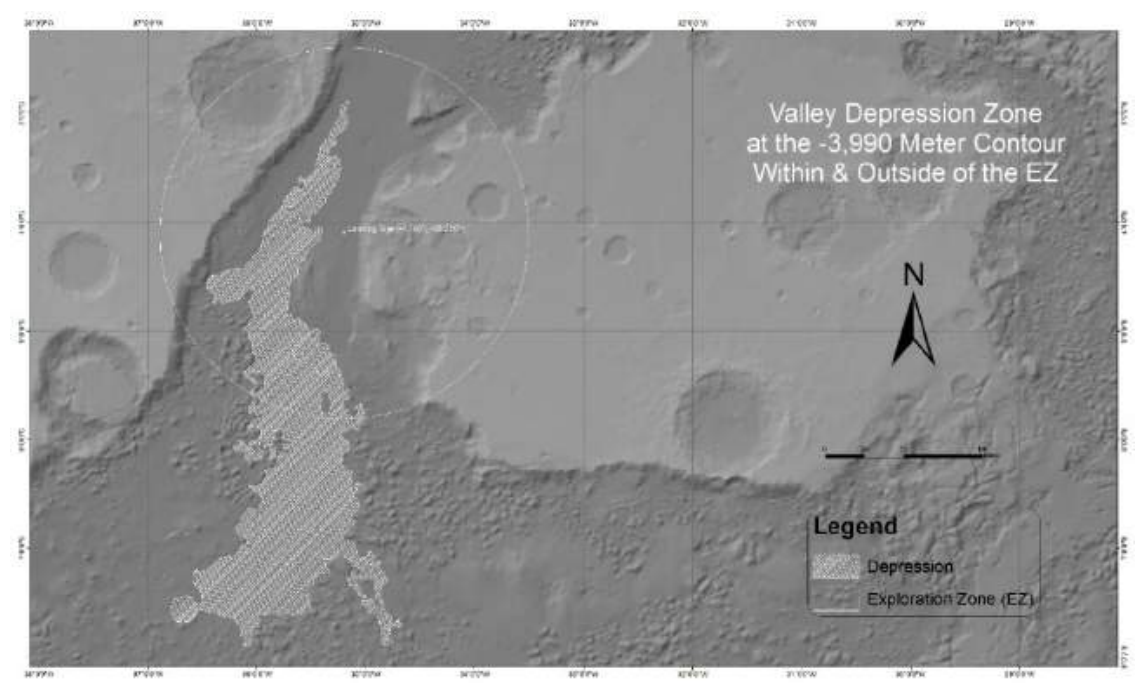

Fig. 8. Map showing depression area as it extends from the Valles Marineris northward into the outflow channel and Exploration Zone.

\subsection{Coordinate Grid}

The coordinate system used on the map was a planetocentric coordinate system called Mars 2000. Using this coordinate system, a latitude and longitude grid was placed over and around the maps data frame to provide a geographical frame of reference.

In addition to the areographic grid, a series of buffer rings were created that radiated from the landing site outward to a distance of 100 kilometers creating a 200kilometer-wide area of exploration. The buffer rings are in increments of 10 kilometers and are symbolized to be apparent but unobtrusive to the map reader. The purpose of these buffer rings are to indicate to explorers on the fly how far away specific geographic or geologic features are from the landing site and to aid in logistics planning for exploration activities. While scale bars are a common map 
element and in most cases necessary for understanding map scale, they are fairly non-intuitive without concerted effort and a linear measuring device. The concentric rings are essentially a modified "scale bar.".

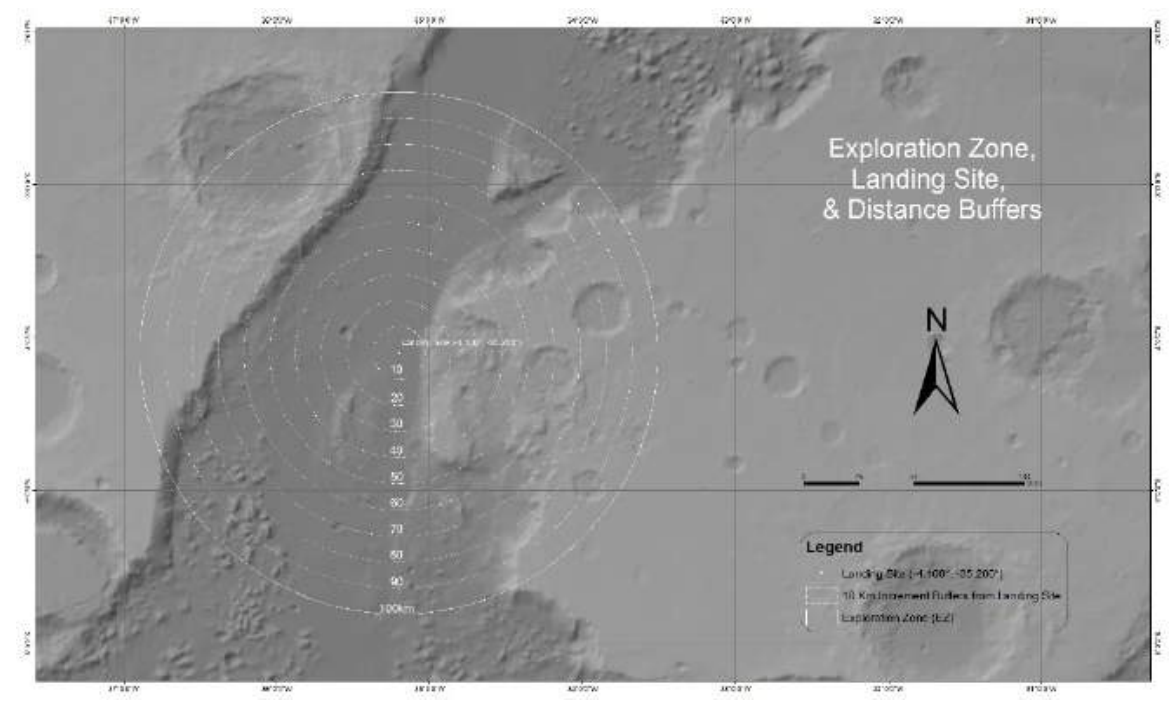

Fig. 9. Map showing $10 \mathrm{~km}$ buffer rings radiating from the land site, which is the center of the Exploration Zone.

\subsection{Nomenclature}

Labeling existing features and places with established and approved nomenclature was a critical part of the development of this map. Proper labeling standards were reviewed (Tanaka et al, 2011) and existing named places were examined from the USGS nomenclature shapefile and Robbin's Crater Database previously mentioned. The USGS nomenclature database contains 1,815 named features and places across the planet Mars that have been approved by the International Astronomical Union (IAU). Only five of which, all craters, were within the Eastern Valles Marineris exploration zone. The Robbins Crater Database showed the same five craters and nothing more. Other features not already approved by the International Astronomical Union (IAU) but that were apparent and overtly displayed within the exploration zone were given preliminary, non-IAU approved names as a matter of due course for this mapping exercise. Whether application for the approval of these names will take place in the future is unknown at this time. 


\subsubsection{Naming Convention}

The names chosen for new places were in keeping with the tradition of commemorating people, Earthly places, and human culture (Hargitai, 2011). Lake Elise, Alderman Bluff, Enge Escarpment, Humboldt Plateau, Hawks Hill, and Ray’s Crater are all named after people who were either famous explorers such as Alexander von Humboldt, or were personally notable to the author. Features such as Clallam Chasma, Pillar Point, and Dungeness Point were named after prominent places in Clallam County of Washington State. West and East craters refer to their relative location to each other, Thalweg crater is a feature found in close proximity to the main valley channel, hence its name. Twin craters are a pair of impact sites nearly on top of each other on the west scree slopes of Exploration Zone, and 70 Kilometer crater represents an impact site nearly exactly 70 kilometers from the Exploration Zone landing site. These prominent features are summarized in the table below.

\begin{tabular}{|c|c|c|}
\hline Feature & Name/Label & Coordinates \\
\hline Paleo lake & Lake Elise & $4^{\circ} 36^{\prime} 10.39 " \mathrm{~S}, 36^{\circ} 20^{\prime} 3.23 " \mathrm{~W}$ \\
\hline Prominent bluff & Alderman Bluff & $3^{\circ} 1^{\prime} 11.34^{\prime \prime} \mathrm{S}, 34^{\circ} 31^{\prime} 49.91^{\prime \prime W}$ \\
\hline Chasma & Clallam Chasma & $3^{\circ} 5^{\prime} 54.92^{\prime \prime} \mathrm{S}, 34^{\circ} 15^{\prime} 11.50^{\prime \prime} \mathrm{W}$ \\
\hline Escarpment & Enge Escarpment & $4^{\circ} 13^{\prime} 48.73^{\prime \prime S}, 34^{\circ} 47^{\prime} 35.95^{\prime \prime W}$ \\
\hline Plateau & Humboldt Plateau & $4^{\circ} 45^{\prime} 7.64^{\prime \prime S}, 34^{\circ} 50^{\prime} 54.73 " \mathrm{~W}$ \\
\hline Stream-lined hill & Hawks Hill & $4^{\circ} 45^{\prime} 7.64^{\prime \prime S}, 34^{\circ} 50^{\prime} 54.73^{\prime \prime W}$ \\
\hline Rim point & Pillar Point & $3^{\circ} 48^{\prime} 25.39^{\prime \prime} \mathrm{S}, 34^{\circ} 47^{\prime} 49.51^{\prime \prime} \mathrm{W}$ \\
\hline Rim point & Dungeness Point & $3^{\circ} 20^{\prime} 53.76^{\prime \prime} \mathrm{S}, 34^{\circ} 15^{\prime} 55.85^{\prime \prime} \mathrm{W}$ \\
\hline Crater & West Crater & $2^{\circ} 46^{\prime} 47.81 " \mathrm{~S}, 36^{\circ} 18^{\prime} 28.56^{\prime \prime}$ \\
\hline Crater & East Crater & $2^{\circ} 47^{\prime} 1.40^{\prime \prime S}, 35^{\circ} 50^{\prime} 30.32 " \mathrm{~W}$ \\
\hline Crater & Ray’s Crater & $3^{\circ} 45^{\prime} 30.38 " \mathrm{~S}, 33^{\circ} 30^{\prime} 38.70^{\prime \prime} \mathrm{W}$ \\
\hline Crater & Thalweg Crater & 358'56.84"S, 35³3'1.98"W \\
\hline Crater & 70 Kilometer Crater & $5^{\circ} 14^{\prime} 41.59^{\prime \prime S}, 35^{\circ} 36^{\prime} 43.15^{\prime \prime W}$ \\
\hline Crater & Twin Craters & $4^{\circ} 5^{\prime} 15.00^{\prime \prime S}, 36^{\circ} 10^{\prime} 57.91 " \mathrm{~W}$ \\
\hline
\end{tabular}

Table 1. List of geographic and geologic features with new place names and corresponding coordinates in the Eastern Valles Marineris outflow region.

\subsection{Lander Sites Inset Map}

To mitigate isolation and potential psychological distress the author decided to illustrate the bearings and distance from the landing site to all other human activity on the planet. This is intended to convey to explorers that they are a part of something larger, something on-going that provides human cultural continuity. These sites were identified on Google Earth's Mars system and exported as a KML file. Once these sites were identified, straight polylines were drawn from the exploration zone to each lander to determine bearing and distance. These lines were also 
exported as a KML file. Both the sites and bearing polyline KML files were then converted to an ESRI shapefile so they could be included on both the primary Eastern Valles Marineris map and the inset global Mars map.

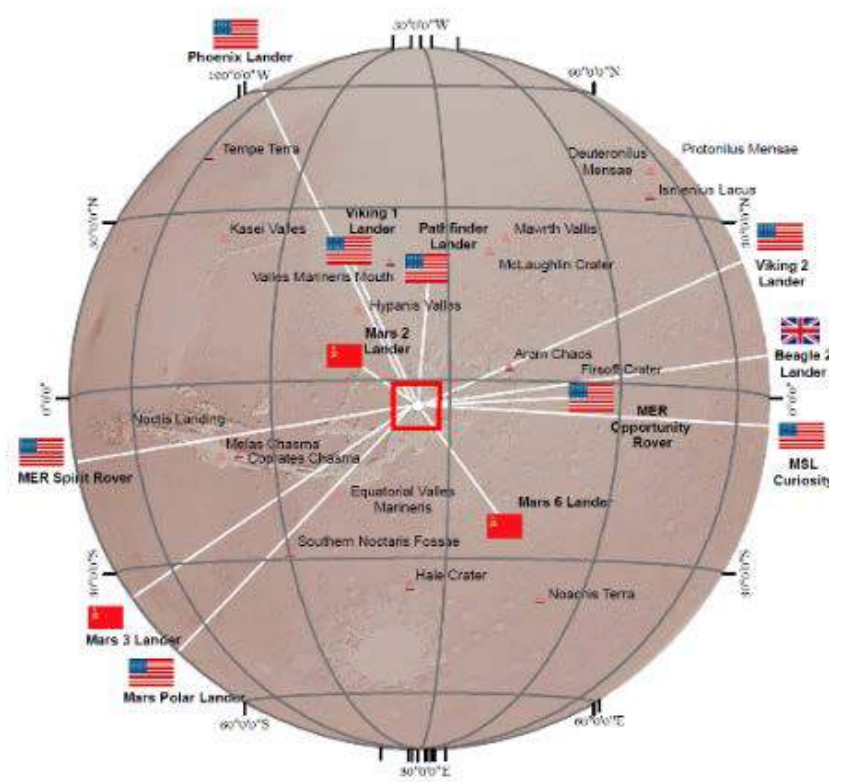

Fig. 10. Global lander site inset map showing landing sites and bearing lines relative to the Eastern Valles Marineris exploration zone as well as the 47 potential land sites and exploration zones identified in 2015 through NASA’s “First Landing Site/Exploration Zone Workshop” (Bussey, 2016).

\section{Conclusions}

Even though cartographic data for remote extra-terrestrial places is difficult to attain, those datasets that are available not only create beautiful cartographic works but also aid in new geographic and geologic discoveries. It's not yet fully known what the future of mapping will look like but it will likely involve a basket of technologies, including hard copy paper maps and posters. This map of the Eastern Valles Marineris Exploration Zone outflow area will hopefully be a useful tool for researchers and enthusiasts alike as the information it contains is used in its current form and eventually gets migrated into future digital mapping interfaces. 


\section{References}

Bussey, B., Hofman, S. (2016). Human Mars Landing Site and Impacts on Mars Surface Operations. https://ntrs.nasa.gov/archive/nasa/casi.ntrs.nasa.gov/20160001040.pdf. PDF. Accessed 21 October 2016.

Chaikin, A. (2012). Is SpaceX Changing the Rocket Equation?. http://www.airspacemag.com/space/is-spacex-changing-the-rocket-equation-132285884/?no-ist. Website. Accessed 17, October 2016.

Google Earth's Mars. (2016). Google Earth program. Downloadable at: https://www.google.com/earth/explore/products/desktop.html. Software download website. Accessed 21, October 2016.

Hargitai, H. I., Shingareva, K. B. (2011). Planetary Nomenclature: A Representation of Human Culture and Alien Landscapes. Advances in Cartography and GIScience. Volume 2. P 275288.International Cartographic Association (ICA) Commission on Planetary Cartography. (2016). Call for maps: Mars Exploration Zone Map Design Competition. https://planetcarto.wordpress.com/2016/04/22/mars-exploration-zone-map-competition/. Website. Accessed 17 October 2016.

Jet Propulsion Laborator (JPL). (2015). NASA, Microsoft Collaboration Will Allow Scientists to 'Work on Mars'. http://www.jpl.nasa.gov/news/news.php?feature=4451. Website. Accessed 10 October, 2016.National Aeronautics and Space Administration. (2016). A Chronology of Mars Exploration . http://history.nasa.gov/marschro.htm. Website. Accessed 17 October 2016.

Neumann, G.A., D.E. Smith, and M.T. Zuber. (2003). Two Mars years of clouds detected by the Mars Orbiter Laser Altimeter, Journal of Geophysical Research, 108(E4), 5023, doi:10.1029/2002JE001849.

Neumann, G.A., Rowlands, D.D., Lemoine, F.G., Smith, D.E., and Zuber, M.T. (2001). Crossover analysis of Mars Orbiter Laser Altimeter data: Journal of Geophysical Research, v. 106, no. E10, p. 23,753-23,768.

Newcomb, D. (2015). Augmented Reality Head-Up Displays Point the Way Toward Self-Driving. http://www.forbes.com/sites/dougnewcomb/2015/10/15/augmented-reality-head-up-displays-point-the-way-toward-self-driving/\#42f844fc77c0. Website. Accessed 17, October 2016)

Robbins, S. (2013). Mars Crater Catalog by Stuart Robbins (20120821). http://astrogeology.usgs.gov/search/map/Mars/Research/Craters/RobbinsCraterDatabase_20120821. Application/zip GIS data for download on website. Accessed 21 October 2016

Tanaka, K. L., Skinner, Jr., J. A., Hare, T. M. (2011). Planetary Geologic Mapping Handbook. http://astrogeology.usgs.gov/search/details/Docs/Mappers/PGM Handbook 2011/pdf. PDF. Accessed 17 October 2016

USGS. (2014). MGS MOLA Elevation Model 463m (MEGDR). http://astrogeology.usgs.gov/search/map/Mars/GlobalSurveyor/MOLA/Mars_MGS_MOLA_DEM_mosaic_global_463m. Website. Accessed 20 October, 2016.

USGS. (2016). Gazetteer of Planetary Nomenclature. http://planetarynames.wr.usgs.gov/GIS Downloads. GIS file metadata. Downloaded and viewed 21 October, 2016. 

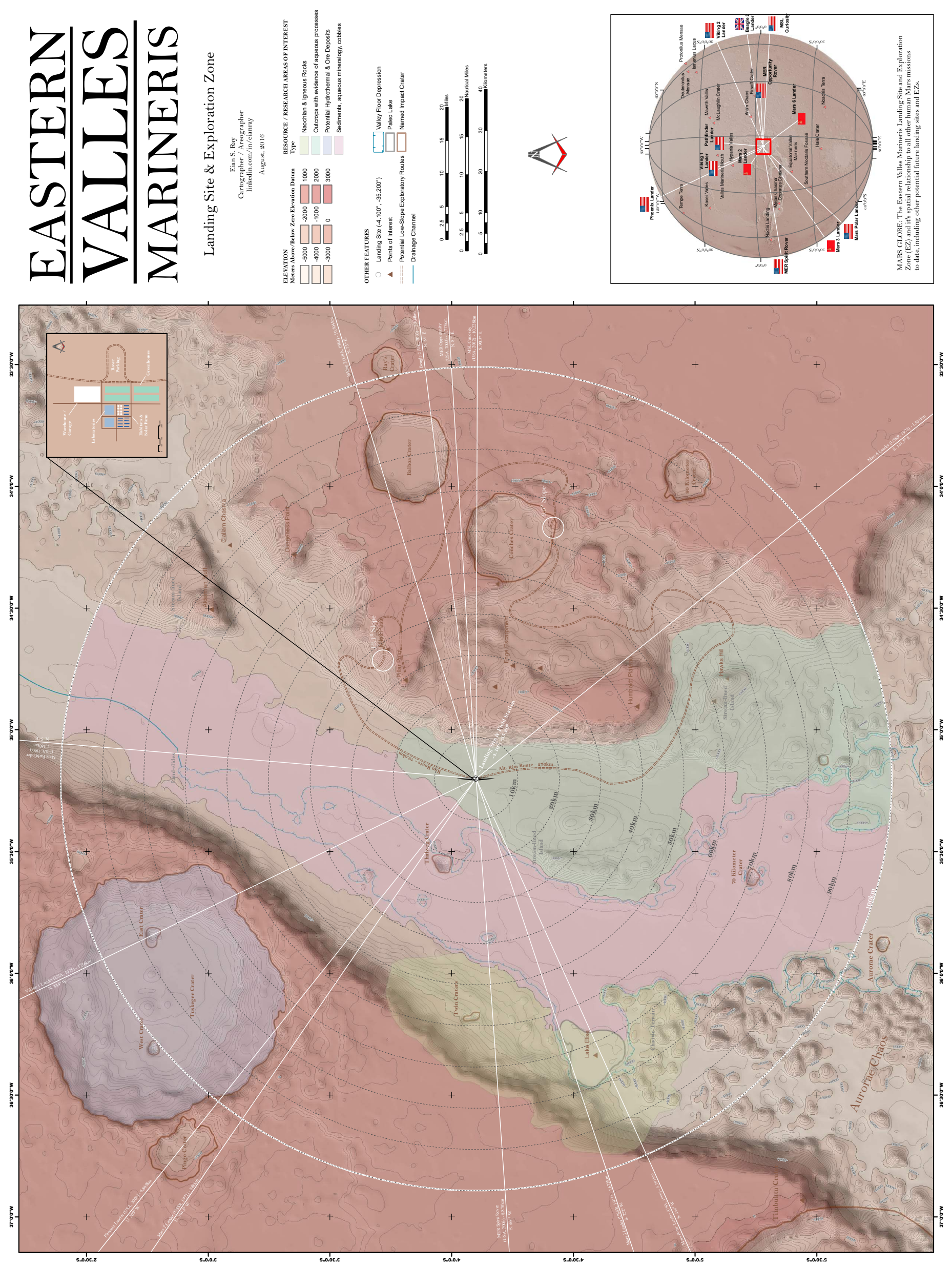

Proceedings of the International Cartographic Association, 2, 2019.

29th International Cartographic Conference (ICC 2019), 15-20 July 2019, Tokyo, Japan. This contribution underwent

single-blind peer review based on submitted abstracts. https://doi.org/10.5194/ica-proc-2-104-2019 | @ Authors 2019. CC BY 4.0 License. 